\title{
A two years retrospective cross-sectional study of donor deferrals in voluntary blood donation camps in a tertiary trauma and orthopaedic centre
}

\author{
Arundhathi. S. ${ }^{1}$, Shanthi Jyothi. K. ${ }^{2}$ \\ ${ }^{1}$ Dr. Arundhathi. S., Assistant Professor of Pathology, ${ }^{2}$ Dr. Shanthi Jyothi. K., Blood Bank Officer, Sanjay Gandhi \\ Institute of Trauma and Orthopaedics, Byrasandra, Jayanagar East, Bengaluru, India. \\ Corresponding Author: Dr. Arundhathi S., Assistant Professor of Pathology, Sanjay Gandhi Institute of Trauma and \\ Orthopaedics, Byrasandra, Jayanagar East, Bengaluru. E-mail id: arundhathi19@yahoo.co.in
}

\begin{abstract}
Introduction: Blood transfusion system is an important component of current modern health care system.Blood transfusion plays a pivotal role in saving lives in medical and surgical conditions and requires a continuous, adequate and safe supply of blood. Materials and Methods: A retrospective, cross sectional descriptive study was conducted on blood donors in voluntary blood donation camps of tertiary trauma and orthopaedic centre over a period of two years. Donors were selected based on the standard guidelines. Predonation screening of donors was done using donor questionnaire, physical examination, haemoglobin estimation and blood grouping. Demographic data were collected from the donor deferral registry. The causes of deferral were categorized as temporary and permanent. Descriptive statistics were used to summarize data. Results: In this two-year study 4,071 donors were registered; 3,668 (90.10\%) qualified for donation and $403(9.90 \%)$ were deferred. Among those who were deferred, females (284, 70.47\%) outnumbered men. Temporary deferrals $(360,89.33 \%)$ were common than permanent deferrals $(43,10.67 \%)$. Low hemoglobin was common cause for temporary deferral $(35.48 \%)$ and hypertension for permanent deferral $(6.45 \%)$. Conclusion: There is a wide spectrum of variation in deferral rates of blood donors and its causes could be due to diversity in donor selection criteria, level of public awareness, environment and socio-economic status. In order to meet demand for blood and its products, blood bank should strive to recruit new donors efficiently and should retain existing donors. Effective measures should be implemented to raise awareness about blood donation and to encourage regular voluntary donations.
\end{abstract}

Keywords: Donor deferral, Blood donation, Temporary deferral, Permanent deferral

\section{Introduction}

Blood transfusion system is an important component of current modern health care system [1].Blood transfusion plays a pivotal role in saving lives in road traffic accidents, maternal hemorrhage, refractory anaemias and other medical and surgical conditions [2]. This requires a continuous, adequate and safe supply of blood from healthy donors. Nearly 81 million units of blood are collected yearly throughout the world according to World Health Organisation (WHO), but, only $39 \%$ are collected in developing countries which contribute to $82 \%$ of population of world [3].

The statistical analysis of National AIDS Control Organization (NACO) showed that annual rate of blood donation is about 7.4 million units in India while the demand is 10 million units [4]. To reduce this mismatch

Manuscript received: $4^{\text {th }}$ March 2019

Reviewed: $14^{\text {th }}$ March 2019

Author Corrected: $20^{\text {th }}$ March 2019 Accepted for Publication: $25^{\text {th }}$ March 2019 in demand and supply of blood units, the judicious selection of donors is required. Thus, this study was conducted to analyse the causes of donor deferral in voluntary blood donation camps.

Identification of causes of donor deferral will help the health care system to adopt measures to increase awareness and to motivate donors which in turn will help to reduce the deficient blood supply.

Hence, this study was conducted to identify the causes of donor deferral in voluntary blood donation camps.

\section{Materials and Methods}

Setting: Voluntary blood donation camps of tertiary trauma and orthopaediccentre

Type: A retrospective, cross sectional descriptive study 
Sampling methods: The study was conducted on blood donors who presented to voluntary blood donation camps of tertiary trauma and orthopediccentre over a period of two years from January 2017 to December 2018. Donors were selected based on the guidelines of Drugs and Cosmetic Act 1940, Directorate General of Health Services guidelines, Ministry of Health \& Family Welfare (2003) and National AIDS Control Organisation (NACO). Pre-donation screening of the donors was done using donor questionnaire followed by physical examination, hemoglobin estimation and blood grouping. Demographic data were collected from the donor deferral registry with respect to age, gender and type of donors. The causes of deferral were categorized as temporary and permanent.

\section{Original Research Article}

Inclusion criteria: All the donors who presented for voluntary blood donation camps were included

Exclusion criteria: Replacement donors were not included

Statistical methods: Descriptive statistics was used to summarize data where frequency tables and cross tabulations were used while describing the data in numbers and percentages.

Ethical consideration: Consent of the donor was taken. Ethical clearance obtained from the institute.

\section{Results}

In two year retrospective, cross sectional study from January 2017 to December 2018; 4,071 donors were registered in voluntary blood donation camps.

They were screened thoroughly and 3,668 (90.10\%) qualified for donation and 403 (9.90\%) were deferred. Among those who were deferred females $(284,70.47 \%)$ out numbered men. Table 1 shows the details of registered, selected and deferred donors.

Table-1: Gender distribution of Registered, Selected and Deferred donors.

\begin{tabular}{|c|c|c|c|}
\hline Donors & Males & Females & Total \\
\hline Registered & $3,486(85.63 \%)$ & $585(14.37 \%)$ & $4,071(100 \%)$ \\
\hline Selected & $3,367(91.79 \%)$ & $301(8.21 \%)$ & $3,668(90.10 \%)$ \\
\hline Deferred & $119(29.52 \%)$ & $284(70.47 \%)$ & $403(9.90 \%)$ \\
\hline
\end{tabular}

Most of the deferrals were in between 18 - 20 years $(233,57.82 \%$ ) followed by 21-30 years. (Table. 2 )

Table-2: Age distribution of deferred donors.

\begin{tabular}{|c|c|c|}
\hline Age (in years) & Total number & Percentage (out of total deferrals=403) \\
\hline$<18$ & 19 & 4.72 \\
\hline $18-20$ & 233 & 57.82 \\
\hline $21-30$ & 111 & 27.54 \\
\hline $31-40$ & 26 & 6.45 \\
\hline $41-50$ & 09 & 2.23 \\
\hline $51-60$ & 05 & 1.24 \\
\hline
\end{tabular}

As most of our blood donation camps were in educational institutions, students formed the predominant deferral group $(317,78.66 \%)$. Predominant deferrals were regular donors accounting for $231(57.32 \%)$.

Overall temporary deferrals $(360,89.33 \%)$ were common than permanent deferrals $(43,10.67 \%)$.

Low hemoglobin was the common cause for temporary deferral $(35.48 \%)$ followed by hypotension, menstruation and under weight (table. 3).

Hypertension was the common cause for permanent deferral (6.45\%) [table.4] 
Original Research Article

Table-3: Causes of Temporary Deferrals and their relative proportions.

\begin{tabular}{|c|c|c|c|}
\hline Causes & Total Number & $\begin{array}{l}\text { Percentage out oftemporary } \\
\text { deferrals (out of } 360 \text { ) }\end{array}$ & $\begin{array}{l}\text { Percentageout of total } \\
\text { deferrals (out of } 403 \text { ) }\end{array}$ \\
\hline Low Hemoglobin & 143 & 39.72 & 35.48 \\
\hline Alcohol intake & 03 & 0.83 & 0.74 \\
\hline Hypotension & 44 & 12.22 & 10.92 \\
\hline Drug intake & 21 & 5.83 & 5.21 \\
\hline Low Weight & 32 & 8.89 & 7.94 \\
\hline Typhoid & 02 & 0.56 & 0.50 \\
\hline Other Infections & 06 & 1.67 & 1.49 \\
\hline Recent donation & 03 & 0.83 & 0.74 \\
\hline Tatooing & 10 & 2.78 & 2.48 \\
\hline Ear piercing & 08 & 2.22 & 1.99 \\
\hline Vaccination & 03 & 0.83 & 0.74 \\
\hline Surgery & 04 & 1.11 & 0.99 \\
\hline Menstruation & 38 & 10.56 & 9.43 \\
\hline Fever & 04 & 1.11 & 0.99 \\
\hline Low age & 19 & 5.28 & 4.71 \\
\hline Allergy & 03 & 0.83 & 0.74 \\
\hline Pregnancy / lactation & 03 & 0.83 & 0.74 \\
\hline Dental extraction & 11 & 3.06 & 2.73 \\
\hline Miscellaneous & 03 & 0.83 & 0.74 \\
\hline Total & 360 & 100 & 89.33 \\
\hline
\end{tabular}

Table- 4: Causes of permanent deferrals and their relative proportions.

\begin{tabular}{|c|c|c|c|}
\hline Causes & Total Number & $\begin{array}{c}\text { Percentage out ofpermanent } \\
\text { deferrals (out of 43) }\end{array}$ & $\begin{array}{c}\text { Percentageout of total } \\
\text { deferrals (out of403) }\end{array}$ \\
\hline Hypertension & 26 & 60.46 & 6.45 \\
\hline Epilepsy & 03 & 6.98 & 0.74 \\
\hline Psychiatric problems & 06 & 13.95 & 1.49 \\
\hline Endocrine disease & 04 & 9.30 & 0.99 \\
\hline Hepatitis B & 04 & 9.30 & 0.99 \\
\hline Total & $\mathbf{4 3}$ & $\mathbf{1 0 0}$ & $\mathbf{1 0 . 6 6}$ \\
\hline
\end{tabular}

\section{Discussion}

Blood transfusion system plays a pivotal role in the current modern health care system. Judicious selection of accurate donors plays a central role for success of safe transfusion practice. Effective guidelines for blood donor recruitment will help to avoid preventable wastage of blood and its products [1]. This helps to conserve resources and reduces the economic burden of the country. The donor deferral in our study was $9.9 \%$ which is little less compared to other studies from India by Kusum D. Jashnani et.al [5], Mourouguessine Vimal et.al [1] and Rehman S et.al [3]. This low deferral rate may be because of young voluntary donors who formed the major bulk in our study.

The prevalence of blood donor deferrals differs from region to region and has a wide spectrum ranging from 4.6 to $30 \%$ [6]. European countries show comparatively less deferral prevalence compared to that of Asia [7]. 
Thus donor deferral is a topic of concern in all nations irrespective of their economic status and this in turn leads to insufficient blood for transfusion as a result of deficiency of suitable blood donors [8].

In our study, females had a higher deferral rate (70.47\%) compared to males. This is comparable to other studies done across the world by Kasraian et.al [6], Arslan et.al [9] and Shazet.al [10]. This could be due to higher prevalence of anaemia among women.

The deferrals were predominantly in the age group of 18 to 20 years $(57.82 \%)$ followed by 21 to 30 years $(27.54 \%)$ and least in group of 51 to 60 years $(1.24 \%)$ unlike study by Valerian DM et.al [2] and Arslan et. al [9]. But our observation was similar to study by Mourouguessine Vimal et.al who reported $56.4 \%$ deferred donors in 18-30 years age group [1].

Comparable results were seen in studies conducted by Lawson et.al [11] and Radhiga et.al [12]. Our observation revealed that in 51-60 years age group the deferral rate is $1.24 \%$ and our donors being of younger age could be the reason.

In our cross-sectional study, temporary deferrals (360, $89.33 \%$ ) were common than permanent deferrals (43, $10.67 \%$ ). This was in concordance with other studies by Rehman et al [3], Custer et al (68.5\%) [13], Shaz et al $(65 \%)$ [10], Lawson et al (91.3\%) [11] and Kasraian et al $(95.5 \%)$ [6].

In our study, anaemia was the predominant cause of temporary deferral and accounted for $39.72 \%$. This was akin to many studies from India [14, 15]. From this observation we can draw a conclusion that clinical and subclinical anaemia is rampant in developing countries like India as well as in other parts of the world $[16,17]$.

The probable causes of anaemia could be poor nutrition, hookworm infestation, low socio-economic status, repeated pregnancies and ignorance [18]. Besides these causes, many studies have proved that regular blood donation can itself significantly contribute to depletion of iron stores leading to iron deficiency anaemia [19]. Thus effective screening programmes, increasing awareness among population and appropriate treatment modalities of anaemia at community blood centres will help to decrease the burden of anaemic deferrals [20].

The other causes of temporary deferral noted in our study are hypotension (12.22\%), menstruation (10.56\%), low weight (8.89\%), drug intake (5.83\%) and under age $(5.28 \%)$. A study by Mourouguessine Vimal et.al reported hypotension as a cause of donor deferral

\section{Original Research Article}

to be $9.7 \%$ [1]. There is lack of substantiating evidence about the adverse events occurring in hypotensive donors. But the increased frequency of syncopal attacks subsequent to blood donation can have a depressing effect on donors and their associates regarding blood donation [21]. Menstruation was third cause for temporary deferral of female donors accounting for $10.56 \%$ unlike $0.6 \%$ in a study by Mourougues sine Vimal et.al [1].

In our study $8.89 \%$ of donors were deferred because of low weight which denotes reduced nutrition and poor health status. About $5.28 \%$ of donors were temporarily deferred as they were less than 18 years of age. They were counseled and were positively encouraged to donate blood after they attain 18 years of age. This highlights the lack of awareness among the youth about criteria for blood donation.

Thus, awareness programmes have to be implemented in educational institutions to improve the knowledge about blood donation and the regulations put forth by statutory bodies regarding donors.

We noted that intake of medications by donors for acute or chronic illnesses accounted for $5.83 \%$ and these were temporarily deferred. Our observation was contradicting results of Unnikrishnan et al who reported a highest percentage $(15.15 \%)$ of medication related deferrals [22].

In our study, permanent deferrals were less accounting for $10.67 \%$. Our observation was similar to results from other studies conducted by Kusum D. J et.al (6.8\%) [5], Custer et.al (10.6\%) [13] and Arslan (10\%)[9] but it is less compared to studies by Mourouguessine Vimal et.al (21.3\%)[1] and Rehman et.al (36.3\%)[3].

Hypertension $(60.46 \%)$ was the predominant cause for permanent deferral but accounted for $6.45 \%$ among total deferrals. Our results correlated with studies by Bahadur et.al [23] and Padma malini et.al [24]. This low incidence of hypertension could be because of our study group being dominated by young donors. The other causes of permanent deferral in our study are depression, endocrine diseases, Hepatitis B and epilepsy.

\section{Conclusion}

From this study we can infer that there is a wide spectrum of variation in deferral rates of blood donors and its causes. This difference could be due to diversity in donor selection criteria, level of public awareness, environment and socio-economic status. In order to 
Original Research Article

meet the demand for blood and its products, blood bank should strive to recruit new donors efficiently and should retain the existing donors. This is possible by educating donors at the community level and by reducing myths and stigma associated with blood donation.

Hence, the need of the hour is to analyse the pattern of donor deferral, recommend revisions regarding donor selection regulations and to encourage retrieval of temporary deferrals. Effective measures should be implemented to raise public awareness about blood donation and to encourage regular voluntary donations.

As our study mainly involved the educational institutions we could understand the varied reasons for donor deferral in younger population and found low hemoglobin as an important cause. Thus, improving the nutritional status of young donors may contribute in improving supply of blood and its products.

\section{Contribution from authors}

- Dr. Arundhathi. S: Data collection, data compiling, literature review, manuscript preparation, final approval

- Dr. Shanthi Jyothi. K: Data collection, manuscript editing, final approval

Funding: Nil; Conflict of Interest: None initiated Permission from IRB: Yes

\section{References}

1.Mourouguessine Vimal, Srinivasan Sowmya, Anandabaskar Nishanthi and Gandhi Ramya. Evaluation of Blood Donor Deferral Causes: A Retrospective Study From South India. Annals of Pathology and Laboratory Medicine, 2016;3 (6): 605-611.

2. Valerian DM, Mauka WI, Kajeguka DC, Mgabo M, Juma A, Baliyima L, et al. Prevalence and causes of blood donor deferrals among clients presenting for blood donation in northern Tanzania. PLoS ONE, 2018; 13(10): e0206487. https://doi.org/10.1371/journal.pone. 0206487

3. Rehman S, Arif SH, Mehdi G, Mirza S, Saeed N, et al. The Evaluation of Blood Donor Deferral Causes: A Tertiary Care Centre-based Study. J Blood Disorders Transf, 2012; 3:131. doi:10.4172/2155-9864.1000131

4. Sareen R, Gupta GN, Dutt A, Sareen R, Gupta GN, Dutt A. Donor awareness: key to successful voluntary blood donation. F1000Research 2012. 1;29.
5. Kusum D. Jashnani and Laxmi N. Patil. Blood donor deferrals: Can this be reduced? Asian J Transfus Sci. 2011 Jan; 5(1): 60. doi: 10.4103/0973-6247.76011.

6. Kasraian L, Negarestani N. Rates and reasons for blood donor deferral, Shiraz, Iran. A retrospective study. Sao Paulo Med J. 2015 Feb;133(1):36-42. doi: 10.1590/ 1516-3180-2013-7110002. Epub 2014 Aug 22.

7. Smith GA, Fisher SA, Dorée C, et al. A systematic review of factors associated with the deferral of donors failing to meet low haemoglobin thresholds. Transfus Med. 2013 Oct; 23 (5):309-20. doi: 10.1111/tme.12046. Epub 2013 Jul 5.

8. Chauhan D, Desai K, Trivedi H, Agnihotri A. Evaluation of blood donor deferral causes: a tertiarycare center-based study. Int. J. Med. Sci. Public Heal. 2015; 4(3): 389-392.

9.Arslan O. Whole blood donor deferral rate and characteristics of the Turkish population. Transfus Med. 2007 Oct;17(5):379-83. Epub 2007 Aug 23. DOI: 10.1111/j.1365-3148.2007.00738.x

10. Shaz BH, James AB, Hillyer KL, Schreiber GB, Hillyer CD. Demographic variations in blood donor deferrals in a major metropolitan area. Transfusion (Paris). 2010 Apr; 50 (4):881-7.

11. Lawson-Ayayi S, Salmi LR. Epidemiology of blood collection in France. Eur J Epidemiol. 1999 Mar; 15 (3): 285-92.

12. Radhiga ST, Kalpana S, Selvakumar, Natarajan MV. Evaluation of Deferral Causes Among Voluntary Blood Donors in Chennai -A Retrospective Study. Int J Med Health Sci. 1357925221;2(1):42-7.

13. Custer B, Johnson ES, Sullivan SD, et al. Community blood supply model: development of a new model to assess the safety, sufficiency, and cost of the blood supply. Med Decis Making. 2005 Sep-Oct; 25 (5): 571-82. DOI: 10.1177/ 0272989 X 05280557

14. Gajjar H, Shah FR, Shah NR, Shah CK. Whole blood donor deferral analysis at General hospital blood bank-A retrospective study. Medicine (Baltimore). 2014; 235:6-13.

15. Taneja K, Bhardwaj K, Arora S, Agarwal A. Analysis of the reasons for deferral of prospective blood donors in a Tertiary Care Hospital in North India. J Appl Hematol. 2015;6(4):154-156. 
16. Tedeschi E, Maria G, Mendrone A, Fátima S, Gualandro M, Cerdeira E, et al. Risk factors for deferral due to low hematocrit and iron depletion among prospective blood donors in a Brazilian center. Rev. Bras. Hematol. 2015;37 (5):306-15.

17. Kumari S, Arya D, Mahawar NL, Bharti A, Sharma L, Das PK, et al. Prevalence and pattern of anemia among persons reported for blood donation at a tertiary care center in western part of Rajasthan. Int. J. Med. Sci. Public Heal. 2016;5 (6):1256-9.

18. Msuya SE, Hussein TH, Uriyo J, et al. Anaemia among pregnant women in northern Tanzania: prevalence, risk factors

19. Newman BH. Adjusting our management of female blood donors: the key to an adequate blood supply. Transfusion. 2004 Apr; 44 (4):591-6. DOI:10.1111/j. 0041-1132. 2004.04014.x

20. Magnussen K, Bork N, Asmussen L. The effect of a standardized protocol for iron supplementation to blood

\section{Original Research Article}

donors low in hemoglobin concentration. Transfusion (Paris). 2008 Apr 1;48(4):749-54.

21. Pauwels NS, Cusack L, De Buck E, et al. The effect of pre-donation hypotension on whole blood donor adverse reactions: a systematic review. J Am Soc Hypertens. 2014 Jun;8(6):429-36. doi: 10.1016/j.jash. 2014. 03.332. Epub 2014 Apr 5.

22. Unnikrishnan B, Rao P, Kumar N, et al. Profile of blood donors and reasons for deferral in coastal South India. Australas Med J. 2011;4(7):379-85. doi: 10.4066/ AMJ. 2011.641. Epub 2011 Jul 31.

23. Bahadur S, Jain S, Goel RK, et al. Analysis of blood donor deferral characteristics in Delhi, India. Southeast Asian J Tro Med Public Health.2009 Sep;40(5):1087-91

24. K. Padma Malini, Tamil Arasi, K. Sudha, O. Shravan Kumar. Evaluation of causes of deferral of blood donors in blood bank- A study of 2 years at tertiary care hospital blood bank. IAIM,2017; 4 (5): 128-132.

\section{How to cite this article?}

Arundhathi. S, Shanthi Jyothi. K. A two years retrospective cross-sectional study of donor deferrals in voluntary blood donation camps in a tertiary trauma and orthopaedic centre. Trop J Path Micro 2019;5(3):150-155.doi:10.17511/jopm. 2019.i03.07. 